\title{
Awareness about adverse drug reaction monitoring and pharmacovigilance among final year medical students in tertiary care teaching hospital in Andhra Pradesh: a cross sectional study
}

\author{
A. P. Narasimha Rao ${ }^{1 *}$, S. Lakshmi $^{2}$ \\ ${ }^{1}$ Department of Pharmacology, ${ }^{2}$ Department of Physiology, Kurnool Medical College, Kurnool, Andhra Pradesh, India
}

Received: 18 December 2019

Revised: 04 February 2020

Accepted: 05 February 2020

*Correspondence:

Dr. A. P. Narasimha Rao,

Email: apnarasimharaokmc@gmai.com

Copyright: (C) the author(s), publisher and licensee Medip Academy. This is an open-access article distributed under the terms of the Creative Commons Attribution Non-Commercial License, which permits unrestricted non-commercial use, distribution, and reproduction in any medium, provided the original work is properly cited.

\begin{abstract}
Background: Adverse drug reaction (ADR) is an unwanted, undesirable effect of a drug that occurs during clinical use. ADRs will occur daily in health care institutions and can unfavourably affect a patient's quality of life, frequently causing considerable morbidity and mortality. Pharmacovigilance is defined as the science and activities relating to the detection, assessment, understanding and prevention of adverse effects or any other drug-related problem.

Methods: It was a non-interventional study was done among hundred final year medical students at Kurnool Medical College, Kurnool, Andhra Pradesh. The study instrument was a predesigned questionnaire was structured by following the precedence, which was set by parallel studies. The participants were given forty-five minutes to answer the questionnaire; the questionnaires were then analyzed by grading the respondents into three categories: poor, unsatisfactory and satisfactory.

Results: This study showed satisfactory results about awareness, knowledge and methods of application of pharmacovigilance among final year medical students 55\%, 47\%, 54\% respectively and positive correlation between awareness, knowledge and methods of application of pharmacovigilance among final year medical students significantly $(<0.0001)$ correlated.

Conclusions: The present study revealed that the final year medical students were satisfactory in awareness and knowledge and methods of application of pharmacovigilance. The correlations told that the higher the awareness, the more was the knowledge and better were the methods of application. Likewise, the knowledge and practices were significantly and positively related to a correlation.
\end{abstract}

Keywords: Adverse drug reaction, Medical students, Pharmacovigilance

\section{INTRODUCTION}

Adverse drug reaction (ADR) is an unwanted, undesirable effect of a drug that occurs during clinical use. ADR seen in healthcare facilities will adversely affect the quality of life of patients. ${ }^{1}$

They may cause patients to lose confidence or develop negative emotions towards their physicians. Additionally,
ADR may promote self-treatment options, which may lead to an increase in further adverse drug reactions. WHO describes pharmacovigilance (PV) as the science and activities related to the identification, assessment, understanding and prevention of any drug-related problem. $^{2}$

PV aims to improve patient safety regarding the use of drugs by providing reliable, balanced information for the 
pragmatic evaluation of the drug's risk-benefit profile. In India, just $1 \%$ of adverse drug reactions are reported. At the same time, in the rest of the world, the reporting rate is $5 \% .^{3}$

Awareness-raising among health care staff about PV improves the reporting of adverse drug reactions in our country. ${ }^{4}$

Therefore, continuous training on ADR reporting regulations for healthcare professionals is necessary. The previously reported study has found that under-reporting of ADR is related to deficits in the knowledge and attitude among healthcare professionals. ${ }^{5-7}$

This study was conducted to evaluate the awareness about ADR monitoring, and methods of application of pharmacovigilance in Kurnool medical college, Kurnool, Andhra Pradesh.

\section{METHODS}

The study was a non-interventional study done among the final year medical students at Kurnool Medical College, Kurnool, Andhra Pradesh. Students who were not willing to participate were excluded from the study. However, prior approval for conducting this study was obtained from the IEC.

The study instrument was a predesigned questionnaire was structured by following the precedence, which was set by similar studies. It was validated. The study questionnaire was designed to assess the awareness, knowledge and methods of application of pharmacovigilance among the study population- the questionnaire comprised of 27 questions (awareness-6, knowledge-9 and methods of application-12).

The questionnaire was administered to 100 final year medical students at KMC, Kurnool. The participants were briefed about the questionnaire, and they were requested to return the duly filled in forms. The participants were given 45 minutes to answer the questionnaire, and they were not allowed to consult anyone during that time. They could maintain anonymity with regards to their names, but they had to write their designations. The questionnaire was designed in such a way that each question had only one correct answer. The answers to the questions were not mutually exclusive. Data collection was carried out for one year from $10^{\text {th }}$ June 2018 to $10^{\text {th }}$ June 2019.

The questionnaires were then analyzed by grading the respondents into three categories: poor, unsatisfactory and satisfactory (Table 1). The questionnaires were then analyzed by classifying the respondents into data from the completed questionnaires are charted categorically in MS Excel sheet, analyzed, and the results are expressed using suitable pictorial representations and percentages.

Table 1: Grading the respondents into three categories: poor, unsatisfactory and satisfactory.

\begin{tabular}{|llll|}
\hline Response & Poor & Unsatisfactory & Satisfactory \\
\hline Awareness & $1-2$ & $3-4$ & $5-6$ \\
\hline Knowledge & $1-3$ & $4-6$ & $7-9$ \\
\hline $\begin{array}{l}\text { Methods of } \\
\text { Application }\end{array}$ & $1-4$ & $5-8$ & $9-12$ \\
\hline
\end{tabular}

\section{RESULTS}

The questionnaire was administered to 100 final year MBBS students. Data from the completed questionnaires are charted categorically in MS excel sheet, analyzed, and the results are expressed using suitable pictorial representations and percentages. The questionnaire was analyzed by giving 1 for the correct response and 0 for the incorrect one. From this study, the following results were obtained.

Table 2 shows the final year medical students $13(13 \%)$ are poor, $32(32 \%)$ are unsatisfactory, $55(55 \%)$ are Satisfactory in the awareness of pharmacovigilance. This is because they were educated about detection, assessment, understanding, and prevention of ADR to a certain extent in their syllabus.

Table 2: Level of awareness, knowledge, application of pharmacovigilance among final year MBBS students.

\begin{tabular}{|llll|}
\hline Grading & Awareness & Knowledge & Application \\
\hline Poor & $13(13 \%)$ & $11(11 \%)$ & $9(9 \%)$ \\
\hline Unsatisfactory & $32(32 \%)$ & $42(42 \%)$ & $37(37 \%)$ \\
\hline Satisfactory & $55(55 \%)$ & $47(47 \%)$ & $54(54 \%)$ \\
\hline
\end{tabular}

In the knowledge regarding the existence of various programs, regional centre, the yellow card system, schedule $\mathrm{Y}$, when to report the adverse event in a clinical trial, etc., The final year MBBS students $11(11 \%)$ are poor, $42(42 \%)$ are unsatisfactory, $47(47 \%)$ are satisfactory in the knowledge of pharmacovigilance.
The final year medical students $9(9 \%)$ are poor, $37(37 \%)$ are unsatisfactory, $54(54 \%)$ are Satisfactory in the application of methods of Pharmacovigilance. This is because they use their little Pharmacovigilance knowledge into the form by their clinical exposure, handling drugs, and managing ADRs in the hospital. 
Table 3 shows the final year MBBS students $1.2 \pm 0.4$ are poor, $3.2 \pm 0.5$ are unsatisfactory, $5.3 \pm 0.4$ are satisfactory in the awareness of pharmacovigilance. $1.8 \pm 0.6$ are poor, $4.9 \pm 0.8$ are unsatisfactory, $8.12 \pm 0.8$ are satisfactory in the knowledge of pharmacovigilance. $2.2 \pm 0.9$ are poor, $6.2 \pm 1.0$ are unsatisfactory, $10.6 \pm 0.9$ are satisfactory in the application of pharmacovigilance.

Table 3: Mean and standard deviation, score of awareness, knowledge, application of pharmacovigilance among final year MBBS students.

\begin{tabular}{|llll|}
\hline Grading & Awareness & Knowledge & Application \\
\hline Poor & $1.2 \pm 0.4$ & $1.8 \pm 0.6$ & $2.2 \pm 0.9$ \\
\hline Unsatisfactory & $3.2 \pm 0.5$ & $4.9 \pm 0.8$ & $6.2 \pm 1.0$ \\
\hline Satisfactory & $5.3 \pm 0.4$ & $8.12 \pm 0.8$ & $10.6 \pm 0.9$ \\
\hline
\end{tabular}

Table 4 shows correlations of awareness and knowledge$\mathrm{r}$ value is 0.818 positively corelated and $\mathrm{p}$ value $<0.0001$ is significant. Awareness and application- $\mathrm{r}$ value is 0.843 positively corelated and $\mathrm{p}$ value $<0.0001$ is significant. Knowledge and application- $r$ value is 0.855 positively corelated and $\mathrm{p}$ value $<0.0001$ is significant.

Table 4: Correlations of awareness, knowledge and methods of application among final year MBBS students.

\begin{tabular}{|llll|}
\hline Variable 1 & Variable 2 & Correlation (r) & P value \\
\hline Awareness & Knowledge & 0.818 & $<0.0001$ \\
\hline Awareness & Application & 0.843 & $<0.0001$ \\
\hline Knowledge & Application & 0.855 & $<0.0001$ \\
\hline$* * *<0.0001$ is significance. & & \\
\hline
\end{tabular}

\section{DISCUSSION}

This study showed satisfactory results about awareness, knowledge and methods of application of pharmacovigilance among final year medical students $55 \%, 47 \%, 54 \%$ respectively and positive correlation between awareness, knowledge and methods of application of pharmacovigilance among final year MBBS students significantly correlated.

Rehan et al conducted a study at Lady Harding Medical College. New Delhi, India and found that the knowledge, attitude and practices of both the undergraduates and the prescribers were comparable, but that they needed further improvement. ${ }^{8}$

Desai et al have conducted a study at the civil hospital, Ahmedabad, concluded that under-reporting and a lack of knowledge about the reporting system were evident among the prescribers. ${ }^{9}$

Gupta et al conducted at two government teaching hospitals, B. J. Medical College, Pune and Seth G.S. Medical College, Mumbai, also revealed that the awareness on the reporting systems was deficient amongst the resident doctors. ${ }^{10}$

Vora et al were conducted. A cross-sectional, questionnaire-based, multi-centric study which was done on six different medical colleges in Gujarat, India, indicated that the overall knowledge of pharmacovigilance was poor in undergraduate medical students. ${ }^{11}$

\section{CONCLUSION}

The present study revealed that the final year medical students are satisfactory in awareness and knowledge and methods of application of pharmacovigilance. However, it was found that they were more skilled in the form which they perform using their meagre knowledge. The correlations revealed that the higher the awareness, the more was the knowledge and better were the methods of application. Likewise, the knowledge and practices were significantly and positively related to a correlation. Therefore, it is a necessity of the hour to implement pharmacovigilance as part of the medical curriculum and also chances of application of knowledge into practice.

Funding: No funding sources

Conflict of interest: None declared

Ethical approval: The study was approved by the Institutional Ethics Committee

\section{REFERENCES}

1. Cobert B. The theory and definitions of drug safety (Pharmacovigilance). In: Cobert's Manual of Drug Safety and Pharmacovigilance, 2nd ed. Sudbury, MA: Jones \& Bartlett; 2012: 4-5.

2. World Health Organization. Quality Assurance and Safety of Medicines Team. Safety of medicines: a guide to detecting and reporting adverse drug reactions: why health professionals need to take action. World Health Organization. 2002. Available at: https://apps.who.int/iris/handle/10665/67378. Accessed 9 June 2018.

3. Prakash S. Pharmacovigilance in India. Indian J Pharmacol. 2007;39:123.

4. Lokesh K. Pharmacovigilance/reporting adverse drug reactions: An approach to enhance health surveillance and extending market share by minimizing the chances of drug withdrawals. Int $\mathbf{J}$ Pharm Sci. 2015;7(9):1-7.

5. Khan SA, Goyal C, Chandel N, Rafi M. Knowledge, attitude and practice of doctors to adverse drug reaction reporting in a teaching hospital in India: An 
observational study. J Nat Sci Biol Med. 2013;4:1916.

6. Muraraiah S, Rajarathna K, Sreedhar D, Basavalingu D, Jayanthi CR. A questionnaire study to assess the knowledge, attitude and practice of Pharmacovigilance in a paediatric tertiary care centre. J Chem Pharm Res. 2011;3:416-22.

7. Buchineni M. Attitude and awareness of ADR reporting among clinicians in a tertiary care hospital a cross-sectional study. Inter J Institut Pharma Life Sci. 2015;5(4):127-30

8. Rehan HS, Vasudev K, Tripathi CD. Adverse drug reaction monitoring: the knowledge, attitude and the practices of the medical students and the prescribers. Natl Med J India. 2002;15(1):24-6.

9. Desai CK, Iyer G, Panchal J, Shah S, Dikshit RK. An evaluation of knowledge, attitude, and practice of adverse drug reaction reporting among prescribers at a tertiary care hospital. Perspect Clini Res. 2011;2(4):129.

10. Gupta P, Udupa A. Adverse drug reaction reporting and pharmacovigilance: knowledge, attitudes and perceptions among the resident doctors. J Pharm Sci Res. 2011;3:1064-69.

11. Vora MB, Paliwal NP, Doshi VG, Barvaliya MJ, Tripathi CB. Knowledge of adverse drug reactions and pharmacovigilance activity among the undergraduate medical students of Gujarat. Inter $\mathrm{J}$ Pharmaceut Sci Res. 2012;3(5):1511.

Cite this article as: Rao APN, Lakshmi S. Awareness about adverse drug reaction monitoring and pharmacovigilance among final year medical students in tertiary care teaching hospital in Andhra Pradesh: a cross sectional study. Int J Basic Clin Pharmacol 2020;9:454-7. 